\title{
Coherentism and Foundationalism in the Practical Domain
}

\author{
Stefano Bertea*
}

\section{Introduction}

In this essay I intend to provide the beginning of an argument for one (admittedly less than orthodox) interpretation of non-global coherentism about practical rationality and reasoning. For the purpose of this work, non-global coherentism can be defined in the negative as any form of coherentism that does not treat coherence as an allencompassing standard, the scope of which extends to any belief, norm, or value we enter into contact with. Contrary to global, or integrated, coherentism, which is presented by its champions as 'a theory of everything', non-global coherentism is a limited and domain-specific theory of truth and normative correctness. ${ }^{1}$ Accordingly, non-global coherentism, which can also be called 'non-integrated coherentism', 'lessthan-all-encompassing coherentism', 'non-pervasive coherentism', or 'non-imperialist coherentism', does not define our basic concepts in terms of what the most coherent theory of everything says that those concepts are. ${ }^{2}$

The contingent opportunity to discuss non-global coherentism is granted by the recent publication of an insightful study of the nature of coherence, The Tapestry

\footnotetext{
* This research was supported by a Marie Curie Intra-European Fellowship within the $7^{\text {th }}$ European Community Framework Programme. The argument set out in this essay was first presented at a symposium on The Tapestry of Reason, held at the School of Law Queen Mary University of London on $26^{\text {th }}$ March 2015. I would like to thank Amalia Amaya, Grant Lamond, William Lucy, Maks del Mar, who also organized the event, and the other participants in the symposium for the most stimulating discussion of coherence-related issues that took place on that occasion.

1 Jaap Hage, 'Three Kinds of Coherentism', in M. Araszkiewicz and J. Šavelka (eds), Coherence: Insights from Philosophy, Jurisprudence and Artificial Intelligence (Kluwer, Dordrecht, 2013, 1-32), 2. See also Jaap Hage and Aleksander Peczenik, 'Legal Knowledge about What?' (2000) 13 Ratio Juris, 326-45.

2 In this essay, the phrases 'non-global coherentism', 'non-integrated coherentism', 'less-thanencompassing coherentism', 'non-pervasive coherentism', and 'non-imperialist coherentism' will be regarded as synonyms.
} 
of Reason, ${ }^{3}$ where, by building on the existing theories of coherence as they have emerged across different disciplines in recent decades, Amalia Amaya develops an original proposal for a comprehensive coherentist approach to legal argument that she appropriately qualifies as non-foundationalist, contextualist, responsibilist, naturalist, explanationist, and non-instrumentalist. ${ }^{4}$ The genuinely interdisciplinary nature of Amaya's work is just one of the noteworthy features that characterize her engagement with the existing debate(s) on coherence. Another distinctive trait of The Tapestry of Reason that one should unreservedly praise is the breadth of scope. In an era when, especially in the Anglo-American world, academics are regrettably pressurized to publish concise essays that are primarily meant to appeal informed audiences (in turn, thought as consisting of interested and intellectually curious non-specialists), and, consequently, can at their best be commended for their originality, brilliance, and readability, as distinct of their ambition and comprehensiveness, Amaya is to be credited for offering a treatment of coherence that is thorough, rigorous, solid, and,

\footnotetext{
${ }^{3}$ Amalia Amaya, The Tapestry of Reason (Oxford, Hart, 2015).

${ }^{4}$ The idea of coherence is deeply ingrained in the practice of contemporary legal systems and has been thoroughly discussed within legal theory in recent decades. Some contributions to the legal debate Amaya enjoins are Neil MacCormick, Legal Reasoning and Legal Theory (Clarendon, Oxford, 1994, original edn 1978); Barbara Baum Levenbook, 'The Role of Coherence in Legal Reasoning', (1984) 3 Law and Philosophy, 355-74; Neil MacCormick, 'Coherence in Legal Justification', in W. Krawietz (ed.), Theorie der Normen (Berlin, Duncker \& Humblot, 1984, 37-53); Ronald Dworkin, Law's Empire (Fontana, London 1986); Robert Alexy and Aleksander Peczenik 'The Concept of Coherence and Its Significance for Discursive Rationality', (1990) 3 Ratio Juris, 130-47, Aleksander Peczenik, 'Coherence, Truth and Rightness in the Law', in P. Nerhot (ed.), Law, Interpretation and Reality (Kluwer, Dordrecht, 1990, 275-309); Vittorio Villa, 'Normative Coherence and Epistemological Presuppositions of Justification', in P. Nerhot (ed.), Law, Interpretation and Reality (Kluwer, Dordrecht, 1990, 431-55); Joseph Raz, 'The Relevance of Coherence', in J. Raz, Ethics in the Public Domain. Essays in the Morality of Law and Politics (Clarendon, Oxford, 1994, 277-325); Robert Alexy, 'Coherence and Argumentation or the Genuine Twin Criterialess Super Criterion', in A. Aarnio et al. (eds), On Coherence Theory of Law (Lund, Juristfoerlaget, 1998, 41-49); Kenneth Kress, 'Coherence', in D. Patterson (ed.), A Company to Philosophy of Law and Legal Theory (Blackwell, Oxford, 1999, 533-52); Veronica Rodriguez-Blanco, 'A Revision of the Constitutive and Epistemic Coherence Theories of Law', (2001) 14 Ratio Juris, 212-32; A. Schiavello, 'On "Coherence" and "Law": An Analysis of Different Models', (2001) 14 Ratio Juris, 233-43; L.M. Soriano, 'A Modest Notion of Coherence in Legal Reasoning. A Model for the European Court of Justice', (2003) 16 Ratio Juris, 296-323; Jaap Hage, 'Law and Coherence', (2004) 17, Ratio Juris, 87-105; Stefano Bertea, 'The Arguments from Coherence', (2005) 25 Oxford Journal of Legal Studies, 369-91; Stefano Bertea, 'Looking for Coherence within the European Community', (2005) 11 European Law Journal, 154-72; Ronald Dworkin, Justice for Hedgehogs (Cambridge, MA, Harvard University Press, 2011); and Stephen Pethick, 'On the Entanglement of Coherence', (2014) 27, Ratio Juris, 116-37.
} 
one may be excused to venture to add, as exhaustive of the issues at stake as it may be possible for scholarship (which is by its nature constitutively incomplete and ever progressing).

A key claim Amaya defends in The Tapestry of Reason is that coherentism should be understood as a superior alternative to formalistic, foundationalist, and sceptical approaches to both theoretical reasoning and practical reasoning. The argument I offer in what follows is intended to not only address this specific claim, which I take to be central to Amaya's project, but also call it into question. More specifically, in this essay I will critically assess the thesis that in the practical domain non-global coherentism, as it is theorized by Amaya, is an alternative to foundationalism. The scope of my discussion of (what I have just introduced as) one of Amaya's central claims is accordingly doubly limited: first, in this essay I do not engage with coherentism in general but only with the less-than-all-encompassing coherentism; second, I explore the role that (Amaya's version of) non-integrated coherentism has the potential to play in justificatory reasoning within the practical domain, while at the same time I abstain from assessing the function coherence may be able to perform in theoretical reasoning. The latter qualification contributes to grant legal relevance to the argument offered here, at least from the perspective of those who conceive of the law and legal reasoning as specific instantiations of practical rationality and practical reasoning respectively. ${ }^{5}$ For, in that perspective, any exploration of the practical dimension of coherence, qua a distinctive justificatory

\footnotetext{
${ }^{5}$ On this tradition of legal studies, the law is conceived as a normative system meant to provide practical guidance, with the result that legal norms figure in some essential way into our reasons for action. On this basis the law is taken to be a particular instantiation, or species, of practical rationality. This conception, which finds an initial statement in H.L.A. Hart's powerful criticism of the 'gunman model' of the law, has become increasingly popular in contemporary legal philosophy. Figuring prominently among those who have defended this conception is Robert Alexy. See, in particular, Robert Alexy, A Theory of Legal Argumentation (Oxford: Clarendon, 1989, original edn 1978), Robert Alexy, 'My Philosophy of Law: The Institutionalisation of Reason', in L.J. Wintgens (ed.), The Law in Philosophical Perspective (Dordrecht: Kluwer, 1999, 23-45); and Robert Alexy, 'The Special Case Thesis', (1999) 12 Ratio Juris, 374-84.
} 
standard shaping deliberation in the practical realm, bears directly on the theory of law and legal reasoning by impacting on Amaya's $(2015,133)$ project to set out a 'unitary coherence-based model of legal reasoning' informed by neither purely instrumentalist assumptions nor foundationalist principles. ${ }^{6}$

2. Coherentism and Foundationalism about Practical Rationality and

\section{Reasoning}

A fundamental tenet shared by coherentist theories of all shapes and colours is the thesis that there is a conceptual link between coherence and coherence-based standards, on the one hand, and rationality and reasoning, on the other. ${ }^{7}$ On a coherentist theoretical framework, coherence is best understood as a constitutive element of rationality and thus as a regulative principle of reasoning. On the received view, from the standpoint of fully-fledged and rigorous forms of coherentism, coherence should, in addition, be taken to be a self-sufficient determinant of rationality and an independent standard of reasoning, to the effect that for a statement to be conceived as rationally justified it will have to be acknowledged as part of a coherent system of beliefs, norms, and values. The normative force of coherence, in other terms, is asserted not to come, and be borrowed, from other, more 'basic', principles on which coherence is claimed to depend. By 'basic principles' I mean principles that are either foundational-namely, non-inferentially justified, selfjustifying, or immediately justified — or based on some appropriate kind of inference from foundational standards. ${ }^{8}$ On this basis, coherentism can be argued to be

\footnotetext{
${ }^{6}$ Amalia Amaya, The Tapestry of Reason (Oxford, Hart, 2015, 133).

${ }^{7}$ The fundamental status this claim has within coherentism clearly emerges from Amaya's treatment throughout The Tapestry of Reason and is, in fact, attested by the very title of that monograph, where the link between coherence and reason is explicitly emphasized.

${ }^{8} \mathrm{I}$ borrow this characterization of the basic standards foundationalism is after from Amalia Amaya, The Tapestry of Reason (Oxford, Hart, 2015, 363).
} 
conceptually irreducible to foundationalism, which, by contrast, is defined as the theoretical perspective shaped by a search for some ground, or foundation, of the normative force of all justificatory standards (including coherence, which is accordingly presented as a neither self-sufficient nor normatively independent principle).

I think that the received view of coherentism, which Amaya accepts, ${ }^{9}$ should be problematized at least in relation to the non-global versions of coherentism. The suggestion that I would like to explore in this section, then, is that the received view is partly misleading, since non-integrated coherentist models of practical rationality and reasoning cannot authentically do without foundationalism and, therefore, should not be regarded as truly independent of, and genuinely alternative to, the foundationalist paradigm in the study of practical rationality and reasoning. Relatedly, in the practical domain non-pervasive coherentism and foundationalism are best understood as complementing each other (as opposed to constituting mutually alternative standpoints).

In order to support these statements I will begin by preliminarily determining the position that the coherence-based conception of practical rationality and reasoning as it is theorized in The Tapestry of Reason - a paradigmatic form of non-imperialist coherentism-occupy within contemporary practical philosophy. Since the

\footnotetext{
${ }^{9}$ For Amaya, 'coherence theories are non-foundationalist in that they reject that there is any set of either factual or normative propositions that provide the basis upon which the justification of the rest of factual ad normative propositions in law depends ... As opposed to coherentism, foundationalism is based on a linear view of inference according to which there are some basic elements (reasons from authority, when reasoning about norms, and propositions that describe evidence, when reasoning about facts) upon which the chains of justifications are based. In contrast, in the holistic view of inference, which coherentism advocates, the justification of any element is a matter of its coherence with the rest of members of the system to which it belongs.' (Amalia Amaya, The Tapestry of Reason (Oxford, Hart, 2015, 545-46)). On this basis, Amaya regards coherentism as a general alternative to foundationalism and, consequently, in her view the acceptance of coherentism commits one to reject foundationalism. This position is explicitly restated in Amaya's argument for her own coherence-driven model of legal rationality and reasoning. See in particular, Amalia Amaya, The Tapestry of Reason (Oxford, Hart, 2015, 471-557).
} 
conceptions of practical rationality and reasoning defended today are manifold, providing an exhaustive overview of them goes well beyond the scope of a short essay. Bringing in one fundamental distinction between traditions of study of practical rationality and reasoning will nonetheless be sufficient for the purpose of setting the stage for my alternative interpretation of non-global coherentism. ${ }^{10}$ In accordance with the fundamental distinction I consider relevant here, the various conceptions of practical rationality and reasoning on offer these days can be distinguished at a general level of abstraction into modest conceptions and ambitious conceptions.

A conception of practical rationality and reasoning is modest, according to this classification, insofar as it associates the capacity for practical deliberation with the (rather limited) power to single out and organize in an orderly fashion the relations among the means for the pursuance of one's practical goals. On the conceptions internal to the modest paradigm, practical rationality and reasoning by themselves do not concern the ends of action, which are given to us by other capacities and processes. This is the case in the twofold sense that practical rationality and reasoning (i) individuate the appropriate means for the pursuing of the relevant practical objectives and (ii) make them consistent overall, by, for instance, ranking the different means available to an agent, subordinating certain means to certain others, weighing and balancing them one against the other, and so on.

The modest paradigm of practical rationality and reasoning finds a paradigmatic statement in instrumentalism, namely, the view that the fundamental principle of practical rationality - the most elemental one and, in fact, the only one that can be

\footnotetext{
${ }^{10} \mathrm{I}$ worked out this distinction by means of a comparative analysis of the essays contained in E. Millgram (eds), Varieties of Practical Inferences (Cambridge MA, MIT Press, 2001). The choice to refer to Millgram's selection is justified not only by the theoretical significance of the contributions collected by Millgram, but also by the fact that Amaya too extensively relies on the collection in her treatment. Accordingly, my choice is also grants some degree of terminological and conceptual uniformity with Amaya's discussion.
} 
grounded beyond doubt - is the so-called instrumental principle. Instrumentalism, accordingly, is committed to the claim that the function of practical rationality and reasoning consists of figuring out what one ought to do in order to best achieve one's goals, as those goals are determined not by rationality and reasoning, but by one's inner states, such as personal desires, preferences, needs, or commitments. ${ }^{11}$ On this view, practical rationality and reasoning are then entrusted with the limited task of proceeding in a teleological fashion from affections to the most effective means one rationally ought to rely on in order to achieve their non-rationally determined goals.

In the family of modest conceptions, practical rationality is not merely confined to deliberating about the effectiveness of one means rather than another. While the instrumentalist variants of the modest paradigm do regard practical reasoning as a mere effective-consideration-led exercise, other conceptions internal to that paradigm give a richer account of reasoning about means. On one of those alternative views, practical deliberation covers not just considerations about the effectiveness of the means chosen, but also considerations about their mutual consistency, coherence, and internal relationships. ${ }^{12}$ Practical rationality, then, is a capacity that can be used to structure and reorganize the multiple means an agent needs resort to in order to achieve their several objectives. Relatedly, considerations from prudence, or self-

\footnotetext{
${ }^{11}$ Instrumentalism is the default positions of neo-Humeans and rational choice theorists, for instance. Statements and defences of this position can thus be found in Elizabeth Anscombe Intention (Cambridge MA, Harvard University Press, 2000, original edn 1957); David Gauthier, 'Reason and Maximization', (1975) 4 Canadian Journal of Philosophy, 411-33; M. Resnik, Choices (Minneapolis, University of Minnesota Press, 1987, 3-20), Robert Audi, Practical Reasoning (London, Routledge, 1989), D. Hubin, 'Irrational Desire', (1991) 62 Philosophical Studies, 23-44; D. Hubin 'What's Special about Humeanism', (1999) 22 Nous, 30-45; and C. Fehige, 'Instrumentalism', in E. Millgram (ed.), Varieties of Practical Reasoning (Cambridge MA, MIT Press, 2001, 49-76). For a general introduction to the Humean theory of practical reason, see Peter Railton, 'Humean Theory of Practical Rationality', in D. Copp (ed.), The Oxford Handbook of Ethical Theory (Oxford, Oxford University Press, 2006, 265-81).

12 This alternative view of modest conception is elaborated on in Michael Bratman, Intentions, Plans and Practical Reason (Cambridge MA, Harvard University Press 1998); Michael Bratman, Faces of Intention (Cambridge, Cambridge University Press 1999); and Michael Bratman, Structures of Agency (Oxford, Oxford University Press, 2007).
} 
interest, which can hardly be reduced to the instrumental principle without distortion, are constitutive of practical rationality and reasoning.

Both the typologies of practical rationality and reasoning just introduced should be qualified as modest since deliberation about means is the least controversial and the most basic form of reasoning about what to do. This form of reasoning defines the minimal kind of practical rationality and deliberation, because denying the capacity to reason about the means necessary to achieve otherwise set ends is tantamount to denying the very capacity to reason: one cannot, without embracing some form of scepticism about practical rationality and reasoning (by so displaying no trust in our capacity to deliberate about practical affairs and, in fact, presenting practical rationality as an impossibility or a figment of imagination), make practical reasoning thinner and practical rationality narrower.

By contrast, ambitious conceptions of practical rationality and reasoning argue that an agent's capacity for rational deliberation is not confined to the management of available means but rather extends to cover the process through which practical ends are set and specified. When compared with modest conceptions, ambitious conceptions broaden the scope of practical rationality and reasoning, which are claimed to have the resources to provide standards for the assessment of one's goals. The scope of practical rationality and reasoning is broadened in two directions. First, in some variants of the ambitious conception (call them the 'robust' versions), practical rationality is taken to be end-related in the specific sense that practical goals are singled out by reason, which contributes decisively to establish the ends of action. Second, in other variants of the ambitious paradigm (call them the 'moderate' versions), practical rationality is acknowledged to have the function of specifying the practical ends an agent may have; that is, practical rationality is functional to 
determining what a far-reaching goal, which is taken to be worthwhile (say, something like life, happiness, good health, etc.), may mean for a particular agent, and, related, practical reasoning is functional to settling the specific meaning a wideranging objective has in the context where the relevant agent operates.

To briefly elaborate on this distinction among species of ambitious conceptions, in the robust versions the main task of practical rationality and reasoning constitutes the ends of action. On this view, practical rationality and reasoning contribute decisively to establish an agent's ends by affecting and modifying their pre-rational desires, preferences, needs, and commitments. Accordingly, the ultimate ends of action are neither irrationally fixed - goals that one may just happen to want, prefer, need, or be committed to, the reasons for such want, preference, need, or commitment being irrelevant—nor given with an intrinsic to-be-pursued feature built into them. This implies that practical rationality and reasoning will be in charge with either discovering certain ends that are to be legitimately regarded as the ultimate onestypically because they are found to be intrinsically sound — or constructing the ends of action according to some rationally constrained procedure. ${ }^{13}$ Relatedly, this version of ambitious conceptions claims that grounds can be provided to other principles of practical rationality and reasoning apart from the instrumental principle and other

\footnotetext{
${ }^{13}$ The first thesis - that practical rationality and reasoning guide us to discover intrinsically valuable ends - is theorized by the champions of ethical realism; the second thesis - that practical rationality and reasoning enable us to construct certain ends as valuable — characterizes instead the theories oriented to ethical constructivism, in particular of the Kantian, or critical rationalist, variety. For a thorough, yet partisan, discussion of realism and constructivism see Christine Korsgaard, The Sources of Normativity (Cambridge, Cambridge University Press, 1996, 28-48 and 90-130), where the latter view is defended. The realist conception of practical rationality and reasoning is endorsed, for example, in Peter Railton, 'Moral Realism', (2006) 45 The Philosophical Review, 163-207; David Brink, Moral Realism and the Foundations of Ethics (Cambridge, Cambridge University Press, 1989), and Thomas Nagel The View from Nowhere (Oxford, Oxford University Press, 1989); the constructivist account is argued for in Thomas Hill, Dignity and Practical Reason (Ithaca, Cornell University Press, 1992, 123-46), Onora O'Neil Constructions of Reason (Cambridge, Cambridge University Press, 1990); Onora O'Neil, Bounds of Justice (Cambridge, Cambridge University Press, 2000, 11-28), Christine Korsgaard, 'The Normativity of Instrumental Reason', in G. Cullity and B. Gaut (eds), Ethics and Practical Reason (Oxford, Oxford University Press, 1997) 215-54; and Andrew Reath, Agency and Autonomy in Kant's Moral Theory (Oxford, Oxford University Press, 2006, 196-230).
} 
means-related principles, such as the principle of prudence or the one prescribing consistency in one's conduct.

The moderate versions of ambitious approaches to practical rationality and reasoning depict the capacity for deliberation as a capacity that applies to the specification of the manifold ends that action may have. ${ }^{14}$ On this view, setting ends is only the first step of one's exercise of practical rationality and reasoning. Ends, once set by rationality, must be specified and contextualized in order to be made operative. As long as ends are merely set in general terms they are not informative enough and, thus, cannot be acted on by specific agents, whose action, then, fails to be genuinely constrained by practical rationality and reasoning. The function of practical rationality and reasoning, thus, does not consist in constituting broad practical goals from which only generic and next-to-empty principles of action can be derived. By contrast, practical rationality and reasoning are there to assist us in choosing specific courses of conduct, namely, in deriving a complete, or nearly complete, set of practical standards that can be used to guide and justify specific choices of those who find themselves to operate in particular contexts.

Now, within a conceptual framework pitting modest paradigms against ambitious paradigms, the non-global coherence-based model of practical rationality and reasoning theorized by Amaya occupies a distinctive position. To begin with, Amaya's proposal should be categorized as an instantiation of the ambitious paradigm, as opposed to an instance of the modest paradigm, because on her view coherence is a standard that guides us not only to reason from (already given) ends to

\footnotetext{
14 This variant of ambitious conceptions of practical rationality is anchored in the Aristotelian philosophical tradition. See, for instance, A. Kolnai, 'Deliberation is of Ends', in E. Millgram (ed.), Varieties of Practical Reasoning (Cambridge MA, MIT Press, 2001, 259-78); and John Finnis, 'Foundations of Practical Reason Revisited', (2005) 50 American Journal of Jurisprudence, 109-31.
} 
means, but also to rationally deliberate about the ends one should pursue. ${ }^{15}$ Appeals to coherence have, more specifically, the potential to discover intelligible connections among one's practical ends and to construct relations of mutual support among those ends. Therefore, of the two variants of the ambitious paradigm introduced aboverobust and moderate-Amaya's non-global coherentism, as I interpret it, sits with the least radical statement of the role rationality and reasoning play in the practical sphere. That is to say, non-integrated coherence-based models of practical rationality and reasoning do not address the deliberative processes aimed at constituting our ends; they instead concern the practices through which our ends are contextualized. In a nutshell, in Amaya's conceptual framework, non-global coherentism is best understood as a moderate variant of the ambitious paradigm, namely, a kind of specificationism about practical ends. On her view, the function that appeals to coherence perform within the practical domain is neither modest in the instrumentalist fashion (since appeals to coherence are concerned with ends, not means) nor ambitious in the robust sense (since appeals to coherence are purported not to establish our ends but to merely specify what goals we rationally ought to pursue).

On the basis of this reconstruction, Amaya (and more generally the advocates of the non-global coherence-based model of practical rationality and reasoning) can be argued to accept that there are two levels of discourse about practical ends. For one thing, there is the 'foundational', or constitutive, discourse, which is concerned with rationally establishing an agent's practical goals; for another, there is the 'specificative', or contextualizing, discourse, which has to do with the deliberation through which the abstract and generic ends rationally constituted in that foundational

\footnotetext{
15 This interpretation of Amaya's position is grounded on her rejection of instrumentalism (see, for instance, Amalia Amaya, The Tapestry of Reason (Oxford, Hart, 2015, 7), combined with her statement concerning the link between 'coherence and reasoning about ends' (Amalia Amaya, The Tapestry of Reason (Oxford, Hart, 2015, 482).
} 
stage should be made operative through the use of reason. The internal distinction between rational discourses about ends-foundational discourse and specificative discourse - that has been so established need not be understood as conceptual. It does not necessarily concern the 'kind', or nature, of reasoning in terms of which each discourse can be categorized; it may well be, by contrast, interpreted as a matter of degree. Moreover, the position a discourse addressed to the ends one ought to rationally pursue takes in relation to other discourses is not necessarily fixed. It may be the case that certain deliberative processes, which are regarded as foundational in a specific domain, are recognized as having a specificative quality in other domains. And yet, despite the fact that the internal distinction between discourses about ends thus drawn may be conceived as being both a mere matter of degree and domaindependent, the distinction is neither unreal nor theoretically insignificant. Insofar as some distinction between different types of rational discourses about ends is established and non-global coherentism about practical rationality and reasoning is acknowledged to only have the resources to specify and contextualize one's ends, as opposed to establish and constitute one's principles of action (by so occupying the specificative level of discourse, vis-à-vis the foundational one), non-integrated coherence-based models of practical rationality and reasoning should not be regarded as alternative to foundationalist models. Coherence-based conceptions instead operate at a different level of discourse when compared to foundationalist approaches.

This statement is of utmost theoretical importance in the context of my argument, since it can be relied on to show that from the standpoint of less-than-allencompassing coherentism the foundationalist project is meaningful, to the effect that engaging in the foundationalist project should be conceived as a natural, perhaps even necessary, complement of any non-global coherence-based theory of practical 
rationality and reasoning. ${ }^{16}$ To briefly elaborate on this statement, if (a) not all rational discourses about practical ends stand on the same footing - some of them are to be acknowledged as practices that contextualize and specify ends established by other reason-based procedures, the nature of which is foundational—and (b) appeals to coherence are, in the perspective of non-integrated coherentism, concerned with the discourses through which ends are specified - coherence is not to be regarded as a standard that can be used to establish an end as rational but rather as a principle one can legitimately employ to derive specific instruction from generic practical directives, possibly constituted by non-coherence-based rational procedures - then (c) within the practical domain non-global coherence-based theories can do without foundations only to some extent. True, coherence-based considerations can provide us with some indication as to which specific ends we ought to rationally pursue without necessarily referring to any ultimate grounds (namely, by simply assuming the validity of that otherwise established ground). From which it follows that coherentism and coherence-based models of practical reasoning are partly autonomous from foundationalist models of practical reasoning. But, at the same time, when performing their distinctive function of specifying the ends of action, appeals to coherence simply bracket and take for granted, vis-à-vis trump, displace, or eliminate, the necessity to refer to foundational procedures aimed at rationally setting ends. The reason supporting this statement is that, insofar as coherence is presented as a normative standard functional to determine the meaning of ends set by other practical principles in a generic and abstract fashion, our appeals to coherence (implicitly) assume the

\footnotetext{
16 This interpretation holds true for non-global coherentism only. By contrast, global coherentism, which is, by definition, a 'theory of everything', is best understood as a theoretical perspective that applies to both the processes aimed at constituting our ends and the practices purported to specify and contextualize those ends.
} 
relevance of the discourse constitutive of the value of the ends coherence appeals to. ${ }^{17}$ The autonomy of non-global coherentism as a theory of practical rationality and reasoning from foundationalism is, accordingly, limited, partial, and, as a matter of fact, merely presumptive. For foundationalism should, on the same count, be understood as the pre-condition of non-imperialist coherentism - the very premise of any less-than-all-encompassing coherentist project-vis-à-vis an approach authentically alternative to non-global coherentism. That is, non-pervasive coherentbased theories of practical rationality and reasoning can only make sense on the basis of the assumption, and on the condition, that some foundation of the values justifying the ends coherence is meant to specify and contextualize is possible. Unless the ends coherence applies to can be established as worthy of being pursued to begin withunless they are somehow constituted, in a foundationalist fashion, as something practically rational agents ought to consider valuable—why should one bother about applying coherence to them in view of specifying them, namely, how could one rationally justify their interest in coherence?

\section{Conclusion}

In this essay I argued that, contrary to a common understanding, within the practical domain coherentism is not necessarily alternative to foundationalism. In my

\footnotetext{
${ }^{17}$ One's principles of action are, in the conceptual framework associated with non-global coherentism, established independently of coherence-based considerations. From which it follows that the endrelated deliberative practices coherence-based forms of reasoning deal with need incorporate, and assume the correctness of, the outcome of more fundamental deliberative processes conceived with setting the ends coherence is then meant to specify. This character of coherence-based reasoning also depends on the fact that coherence itself is a derivative value. Far from being valuable in itself coherence is best understood as something 'to be valued as long as it helps us to achieve a variety of cognitive and practical goals', such as truth, correctness, coordination, efficacy, certainty, predictability, conflict resolution, personal identity, integrity, and unity (Amalia Amaya, The Tapestry of Reason (Oxford, Hart, 2015, 482). On the derivative nature of coherence, see also Neil MacCormick, 'Coherence in Legal Justification', in W. Krawietz (ed.), Theorie der Normen (Berlin, Duncker \& Humblot, 1984, 39-42) and H. Richardson, Practical Reasoning about Final Ends (Cambridge, Cambridge University Press, 1994, 152-58).
} 
argument, I did not defend the sweeping view that any form of coherentism fails to be a genuine alternative to foundationalism. ${ }^{18}$ The claim I set out to defend in this work has a more modest quality: I argued that non-global coherentism cannot do without a distinction among discourses about practical ends, some of which will have to be regarded as more fundamental than others. The internal distinction among types of discourses concerning practical ends is important not only in consideration of the fact that it commits us to establish which discourse is foundational and which discourse is merely meant to specify the ends an agent has, but also in consideration of the fact that coherence-based considerations constitutively belong to the latter type of discourse. And, insofar as one concedes that less-than-all-embracing coherence-based models of practical rationality and reasoning are concerned with discourses about ends that occupy a less than foundational position in the normative landscape, (nonglobal) coherentism can be claimed to assume the existence of, and be based on, some model of practical rationality and reasoning that has the resources to set the general goals we ought to pursue, namely, to ground our ends, or establish their ultimate value. This means that the project of exploring the grounds of our goals should be acknowledged to be far from arbitrary or ruled out by one's embracement of nonglobal coherentism. Since within the practical sphere foundationalism (at its best) is exactly the attempt to ground the rational status of certain values and norms as noninferentially justified, non-integrated coherentism calls for and requires foundationalism, as opposed to displacing it and making it irrelevant. Within the practical sphere, therefore, non-imperialist coherentism should be understood as a view that builds on the premises set out by foundationalism, of which discourses it

\footnotetext{
${ }^{18}$ Indeed, I am convinced that the global and integrated versions of coherentism are best conceived as constituting an authentically alternative paradigm to foundationalism. An influential statement of global coherentism can be found in Ronald Dworkin, Justice for Hedgehogs (Cambridge MA, Harvard University Press, 2011).
} 
assumes the theoretical significance, vis-à-vis a view that is an alternative to foundationalism. This conclusion goes against the received view-a view that The Tapestry of Reason shares - that coherentism in all its forms (including the non-global ones) is alternative to foundationalism. 